\title{
ON APPROXIMATION OF CONTINUOUSLY DIFFERENTIABLE FUNCTIONS BY POSITIVE LINEAR OPERATORS
}

\author{
Heinz H. Gonska
}

\begin{abstract}
The aim of this note is to prove a theorem on the pointwise degree of approximation of continuously differentiable functions by positive linear operators. As can be seen from the applications to Bernstein and Hermite-Fejér operators, our inequality yields better constants and sometimes even a higher degree of approximation than the known general results.
\end{abstract}

Recently Mond and Vasudevan [13] proved a refined version of a theorem of Censor [3] concerning the approximation of functions in $c^{l}[a, b]$ by positive linear operators. This improvement which is also due to Meier [10] can be obtained by proceeding in the same way as was done by Mond [12] who modified the well known result of Shisha and Mond [17].

It is the aim of the present note to indicate that there is a further improvement over Censor's result which yields better constants than the theorem of Mond and Vasudevan and which guarantees for certain positive linear operators even a higher degree of approximation. Moreover, the assumption that $\left\{L_{n}(1)\right\}_{n=1}^{\infty}$ is uniformly bounded is superfluous.

Following De Vore [4] we prove a pointwise statement.

THEOREM. Let $L$ be a linear positive operator on $c[a, b]$. Let $f \in C^{l}[a, b]$ and let $w\left(f^{\prime}, \cdot\right)$ be the modulus of continuity of $f^{\prime}$.

Received 9 August 1982. 
Then the estimate

$$
\begin{aligned}
|L(f, x)-f(x)| \leq|f(x)| \cdot \mid & \left|L\left(e_{0}, x\right)-1\right|+\left\|f^{\prime}\right\| \cdot\left|L\left(e_{1}-x, x\right)\right| \\
& +\left[L\left(\left|e_{1}-x\right|, x\right)+\frac{1}{2 h} \cdot L\left[\left(e_{1}-x\right)^{2}, x\right]\right] \cdot w\left(f^{\prime}, h\right)
\end{aligned}
$$

holds, where $e_{i}$ denotes the $i$ th monomial, $h \in(0, b-a)$ is arbitrarily chosen, and $\|\cdot\|$ denotes the sup-norm.

Proof. First observe that

$$
|L(f, x)-f(x)| \leq\left|L(f, x)-f(x) \cdot L\left(e_{0}, x\right)\right|+|f(x)| \cdot\left|L\left(e_{0}, x\right)-1\right| .
$$

Thus it remains to estimate the difference $L(f, \cdot)-f(\cdot) \cdot L\left(e_{0}, \cdot\right)$.

Since $f$ is in $C^{\mathcal{I}}[a, b]$ and $L$ is a positive linear operator we know for each $x \in[a, b]$ that

$$
\begin{aligned}
\left|L(f, x)-f(x) \cdot L\left(e_{0}, x\right)\right| & =|L(f-f(x), x)| \\
& \leq L(|f-f(x)|, x) \\
& \leq\left\|f^{\prime}\right\| \cdot L\left(\left|e_{1}-x\right|, x\right) .
\end{aligned}
$$

This inequality is due to Mamedov [9].

Moreover, let $g \in c^{2}[a, b]$. In this case we have $\left|L(g, x)-g(x) \cdot L\left(e_{0}, x\right)\right| \leq \frac{1}{2} \cdot L\left(\left(e_{1}-x\right)^{2}, x\right) \cdot\left\|g^{\prime \prime}\right\|+\left|L\left(e_{1}-x, x\right)\right| \cdot\left\|g^{\prime}\right\|$.

This type of estimate can be traced to De Vore [4] and, independently, Min'kova [11].

Now let $f \in C^{I}[a, b]$. Considering again the difference $L(f, \cdot)-f(\cdot) \cdot L\left(e_{0}, \cdot\right)$ we have for an arbitrary $g$ in $c^{2}[a, b]$,

$$
\begin{aligned}
\mid L(f, x)-f(x) & \cdot L\left(e_{0}, x\right) \mid \\
\leq & \left|L(f-g, x)-(f-g)(x) \cdot L\left(e_{0}, x\right)\right|+\left|L(g, x)-g(x) \cdot L\left(e_{0}, x\right)\right| \\
\leq & \left\|(f-g)^{\prime}\right\| \cdot L\left(\left|e_{1}-x\right|, x\right)+\left\|g^{\prime \prime}\right\| \cdot \frac{1}{2} \cdot L\left(\left(e_{1}-x\right)^{2}, x\right) \\
& +\left\|g^{\prime}\right\| \cdot\left|L\left(e_{1}-x, x\right)\right| .
\end{aligned}
$$

Now we extend $f^{\prime}$ to a function $\bar{f}^{\prime}$ by defining $\bar{f}^{\prime}(x)=f^{\prime}(a)$ for $x<a$ and $\bar{f}^{\prime}(x)=f^{\prime}(b)$ for $x>b$. Putting 


$$
\left(f^{\prime}\right)_{h}(x):=\frac{1}{2 h} \int_{-h}^{h} \bar{f}^{\prime}(x+u) d u
$$

for $0<h \leq b-a$ and $x \in[a, b]$ yields a function $\left(f^{\prime}\right)_{h}$ satisfying the inequalities

$$
\left\|f^{\prime}-\left(f^{\prime}\right)_{h}\right\| \leq w\left(f^{\prime}, h\right) \text { and }\left\|\left(f^{\prime}\right)_{h}^{\prime}\right\| \leq \frac{l}{h} \cdot w\left(f^{\prime}, h\right) .
$$

If we now choose $g \in C^{2}[a, b]$ in such a way that $g^{\prime}=\left(f^{\prime}\right)_{h}$ we arrive at

$$
\begin{aligned}
& \left|L(f, x)-f(x) \cdot L\left(e_{0}, x\right)\right| \\
& \begin{aligned}
& \leq w\left(f^{\prime}, h\right) \cdot L\left(\left|e_{1}-x\right|, x\right)+\frac{1}{h} \cdot w\left(f^{\prime}, h\right) \cdot \frac{1}{2} \cdot L\left(\left(e_{1}-x\right)^{2}, x\right) \\
&+\left\|f^{\prime}\right\| \cdot\left|L\left(e_{1}-x, x\right)\right| \\
&=\left\|f^{\prime}\right\| \cdot\left|L\left(e_{1}-x, x\right)\right|+\left[L\left(\left|e_{1}-x\right|, x\right)+\frac{1}{2 h} \cdot L\left(\left(e_{1}-x\right)^{2}, x\right] \cdot w\left(f^{\prime}, h\right) .\right.
\end{aligned}
\end{aligned}
$$

From this the desired inequality follows.

Note that if $L$ reproduces the zero-th or the zero-th and the first monomial at a fixed point $x$, this theorem gives a much simpler estimate. This is the case for the polynomial operator introduced by Bernstein [2] which will be treated in the following

EXAMPLE. For the classical Bernstein operators given for $f \in \mathbb{R}^{[0,1]}$ by

$$
B_{n}(f, x):=\sum_{k=0}^{n} f(k / n) \cdot\left(\begin{array}{l}
n \\
k
\end{array}\right) x^{k}(1-x)^{n-k}
$$

for $f \in C^{l}[0, I], x \in[0,1]$ and $n \geq 1$ the following inequalities hold:

(i)

$$
\begin{aligned}
& \left.\left|B_{n}(f, x)-f(x)\right| \leq\left\{\left.\frac{2}{n}(n-r)\right|_{r} ^{n}\right) x^{r+1}(1-x)^{n-r}+\frac{x(1-x)}{2 \sqrt{n}}\right\} \cdot w\left(f^{\prime}, \frac{1}{\sqrt{n}}\right) ; \\
& \quad \text { here } r \text { is given by } r=[n x] \text { where }[n x] \text { denotes the } \\
& \quad \text { largest integer not exceeding } n x ;
\end{aligned}
$$


(ii) $\left\|B_{n} f-f\right\| \leq \frac{5}{\theta} \cdot \frac{1}{\sqrt{n}} \cdot w\left(f^{\prime}, \frac{1}{\sqrt{n}}\right)$.

Proof. The important representation of $B_{n}\left(\left|e_{1}-x\right|, x\right)$ was given by Schurer and Steutel [15]; the equality $B_{n}\left(\left(e_{1}-x\right)^{2}, x\right)=x(1-x) / n$ is well known. This gives (i). In order to arrive at (ii) it is not necessary to use (i).

Using the Cauchy-Schwartz inequality (which can give quite a crude estimate) one has

$$
B_{n}\left(\left|e_{1}-x\right|, x\right) \leq\left(B_{n}\left(\left(e_{1}-x\right)^{2}, x\right)\right)^{\frac{1}{2}} .
$$

This leads to the estimate

$$
\left|B_{n}(f, x)-f(x)\right| \leq\left(\frac{1}{2 \sqrt{n}}+\frac{1}{8 \cdot \sqrt{n}}\right) \cdot w\left(f^{\prime}, \frac{1}{\sqrt{n}}\right)=5 \cdot \frac{1}{\sqrt{n}} \cdot w\left(f^{\prime}, \frac{1}{\sqrt{n}}\right)
$$

which was claimed under (ii).

Thus, by employing the above smoothing approach we arrive at an estimate for the approximation by Bernstein polynomials which is better than the corresponding application of the theorem of Mond and Vasudevan. The following remark shows that our approach gives always better constants provided that $L\left(e_{0}, x\right)=1$ and $L\left(e_{1}, x\right)=x$ for $x \in[a, b]$ fixed.

$$
\text { If } L\left(e_{i}, x\right)=e_{i}(x) \text { for } i=0,1 \text {, and if we choose } h=A \cdot \mu \text {, }
$$
$A>0$, where $\mu=\left\|L\left((e,-\cdot)^{2}, \cdot\right)\right\|^{\frac{1}{2}}>0$, then

$$
\begin{aligned}
L\left(\left|e_{1}-x\right|, x\right)+\frac{1}{2 A \mu} \cdot L\left(\left(e_{1}-x\right)^{2}, x\right) & \leq \mu+\frac{1}{2 A \mu} \cdot \mu^{2} \\
& <\left(\frac{1}{A}+1\right) \mu .
\end{aligned}
$$

Thus the above approach yields an estimate which - for the particular case of Bernstein operators - comes close to the striking result of Schurer and Steutel [16] concerning the best possible constant in an estimate of the above type. We take the liberty to point out that the gap between our general theorem and the particular Bernstein polynomial approach due to Schurer and Steutel was bridged in our paper [7] by using the least concave majorant of $w\left(f^{\prime}, \cdot\right)$. 
The next example shows that our theorem yields a higher degree of approximation for differentiable functions than the theorem of Mond and Vasudevan does provided that $L\left(\left|e_{1}-x\right|, x\right)$ is small in comparison to $\left(L\left(\left(e_{1}-x\right)^{2}, x\right)\right)^{\frac{1}{2}}$.

EXAMPLE. If we consider the classical Hermite-Fejér polynomials $H_{n}(f, \cdot)$ of Fejér [5] interpolaiing a function $f \in \mathbb{R}^{[-1,1]}$ at the zeros of the Čebyšev polynomials $T_{n}$ and having a derivative equal to zero at these points, that is,

$$
H_{n}(f, x)=\sum_{k=1}^{n} f\left(x_{k}\right) \cdot \frac{\left(1-x x_{k}\right) \cdot T_{n}(x)^{2}}{n^{2} \cdot\left(x-x_{k}\right)^{2}}
$$

where

$$
x_{k}=\cos ((2 k-1) \pi / 2 n) \text {, }
$$

for $f \in c^{1}[-1,1], x \in[-1,1]$ and $n \geq 2$, the following inequalities hold:

$$
\begin{aligned}
& \left|H_{n}(f, x)-f(x)\right| \leq \frac{1}{n}\left|T_{n}(x) \cdot T_{n-1}(x)\right| \cdot\left\|f^{\prime}\right\|+\frac{C_{1}}{n}\left|T_{n}(x)\right| \\
& \text { - }\left(1+\sqrt{1-x^{2}} \cdot \log n\right) \cdot w\left(f^{\prime}, \frac{\left|T_{n}(x)\right|}{1+\sqrt{1-x^{2}} \cdot \log n}\right) \text {, } \\
& \text { (ii) }\left\|H_{n} f-f\right\| \leq \frac{1}{n} \cdot\left\|f^{\prime}\right\|+\frac{C_{2^{\log n}}}{n} \cdot w\left(f^{\prime}, \frac{1}{\log n}\right) \text {. }
\end{aligned}
$$

Here $C_{1}$ and $C_{2}$ are suitable constants.

Proof. In order to evaluate $H_{n}\left(\left|e_{1}-x\right|, x\right)$ we use a recent result of Goodenough and Mills [8] (see also Amel'kovic [1]); from their Theorem 7 we obtain (with real numbers $C_{3}, C_{4}, \ldots$ ) the inequalities 


$$
\begin{aligned}
H_{n}\left(\left|e_{1}-x\right|, x\right) & \leq \frac{C_{3}}{n} \cdot T_{n}(x)^{2}\left(\sum_{k=1}^{n} \frac{\left(1-x^{2}\right)^{\frac{3}{2}}}{k}+\frac{1}{k^{2}}\right)+C_{4} \cdot \frac{\left|T_{n}(x)\right|}{n} \\
& \leq \frac{C_{5}}{n}\left|T_{n}(x)\right| \cdot\left(1+\left(1-x^{2}\right)^{\frac{1}{2}} \cdot \log n\right) .
\end{aligned}
$$

Using the equalities (see [6], [14])

$$
H_{n} e_{0}=e_{0}, H_{n}\left(e_{1}-x, x\right)=-\frac{1}{n} \cdot T_{n}(x) \cdot T_{n-1}(x)
$$

and

$$
H_{n}\left(\left(e_{1}-x\right)^{2}, x\right)=\frac{1}{n} \cdot T_{n}^{2}(x)
$$

our above theorem yields the estimate $(0<h \leq 2)$

$$
\begin{aligned}
& \left|H_{n}(f, x)-f(x)\right| \leq \frac{1}{n} \cdot\left|T_{n}(x) \cdot T_{n-1}(x)\right| \cdot\left\|f^{\prime}\right\| \\
& \quad+\left[\frac{C_{5}}{n} \cdot\left|T_{n}(x)\right| \cdot\left(1+\left(1-x^{2}\right)^{\frac{1}{2}} \cdot \log n\right)+\frac{1}{2 h} \cdot \frac{1}{n} \cdot \frac{T^{2}}{{ }^{2}}(x)\right] \cdot w\left(f^{\prime}, h\right) .
\end{aligned}
$$

Choosing

$$
h=\frac{\left|T_{n}(x)\right|}{1+\sqrt{1-x^{2}} \cdot \log n} \leq 1 \text { for } T_{n}(x) \neq 0
$$

we arrive at

$$
\begin{aligned}
\left|H_{n}(f, x)-f(x)\right| & \leq \frac{1}{n} \cdot\left|T_{n}(x) \cdot T_{n-1}(x)\right| \cdot\left\|f^{\prime}\right\| \\
& +\frac{C_{1}}{n}\left|T_{n}(x)\right| \cdot\left(1+\left(1-x^{2}\right)^{\frac{1}{2}} \cdot \log n\right) \cdot w\left(f^{\prime}, \frac{\left|T_{n}(x)\right|}{1+\sqrt{1-x^{2}} \cdot \log n}\right) .
\end{aligned}
$$

Due to the fact that $H_{n} f$ interpolates at the zeros of $T_{n}$ this inequality is also true if $T_{n}(x)=0$. This gives statement $(i)$ in our example.

The uniform assertion under (ii) follows from the particular choice $h=1 /(\log n)$. Proceeding in exactly the same way as above we get for all $x \in[-1,1]$, 


$$
\begin{aligned}
\left|H_{n}(f, x)-f(x)\right| & \leq \frac{1}{n} \cdot\left\|f^{\prime}\right\|+\frac{C_{6}}{n}(\log (e \cdot n)+\log n) \cdot w\left(f^{\prime}, \frac{1}{\log n}\right) \\
& \leq \frac{1}{n} \cdot\left\|f^{\prime}\right\|+C_{2} \cdot \frac{\log n}{n} \cdot w\left(f^{\prime}, \frac{1}{\log n}\right) .
\end{aligned}
$$

COROLLARY. If $f \in C^{l}[-1,1]$ such that $f^{\prime} \in \operatorname{Lip} \alpha, 0<\alpha \leq 1$, then

$$
\left\|H_{n} f-f\right\|=0\left(\frac{(\log n)^{\perp-\alpha}}{n}\right), n \rightarrow \infty
$$

Thus the estimate in our second example gives a pointwise extension of the theorem of Goodenough and Mills to continuously differentiable functions in the sense that it takes both aspects into account: it expresses the fact that we are dealing with interpolation operators and at the same time reproduces the best available order of approximation of functions whose derivative is in Lip $\alpha$. This emphasizes - once again the need for theorems on how close the estimate in the corollary is to best possible.

\section{References}

[1] В.Г. Амелтнович [V.G. Amel'kovič], "О порядке приблинения непрерывных функций интерполяционњми полиномами Фейера-Ормнта" [on the order of approximation of continuous functions by Fejér-Hermite interpolation polynomials", Polytechn. Inst. Odessa Naün. Zap. 34 (1961), 70-77.

[2] S. Bernstein, "Démonstration du théoreme de Weierstrass, fondée sur le calcul des probabilitiés", Charkow Ges. (2) 13 (1912), 1-2.

[3] Erga Censor, "Quantitative results for positive linear approximation operators", J. Approx. Theory 4 (1971), 442-450.

[4] Ronald A. DeVore, The approximation of continuous fronctions by positive linear operators (Lecture Notes in Mathematics, 293. Springer-Verlag, Berlin, Heidelberg, New York, 1972).

[5] Leopold Fejér, "Ueber Interpolation", Nachr. Ges. Wissensch. cöttingen (1916), 66-91. 
[6] Heinz Herbert Gonska, "Quantitative Aussagen zur Approximation durch positive lineare Operatoren" (Dissertation, Universität Duisburg, 1979).

[7] Heinz H. Gonska and Jutta Meier, "On approximation by Bernstein type operators: best constants", submitted.

[8] S.J. Goodenough and T.M. Mills, "A new estimate for the approximation of functions by Hermite-Fejér.interpolation polynomials", $J$. Approx. Theory 31 (1981), 253-260.

[9] Р.Г. Мамедов [R.G. Mamedov], "О порядке гриближений функцй линейнњми Полоаителыњми опеоаторами" [on the order of approximation of functions by linear positive operators], Dokl. Akad. Nauk SSSR 128 (1959), 674-676.

[10] Jutta Meier, "Zur Verallgemeinerung eines Satzes von Censor und DeVore", submitted.

[11] P.M. Mинькоlia [R.м. Min'kova], "Сходимость произволыш линейньх операторов" [Convergence of the derivatives of linear operators], Izv. Vyšs. Učebn. Zaved. Matematika (1976), no. 8, $52-59$.

[12] B. Mond, "On the degree of approximation by linear positive operators", J. Approx. Theory 18 (1976), 304-306.

[13] B. Mond and R. Vasudevan, "On approximation by linear positive operators", J. Approx. Theory 30 (1980), 334-336.

[14] Tiberiu Popoviciu, "Asupra demonstratiei teoremei Iui Weierstrass cu ajutorul polinoamelor de interpolare", Lucrarile sesiunii generale stiintifice, 2-12 iunie 1950, 1664-1667 (Editura Academiei Republicii Populare Române, București, 1951).

[15] F. Schurer and F.W. Steutel, "On the degree of approximation of functions in $C^{l}[0,1]$ by Bernstein polynomials" (T.H. Report 75-WSK-07. Onderafdeling der Wiskunde, Technische Hogeschool Eindhoven, The Netherlands, 1975).

[16] F. Schurer and F.W. Steutel, "The degree of local approximation of functions in $C_{1}[0,1]$ by Bernstein polynomials", J. Approx. Theory 19 (1977), 69-82. 
[17] 0. Shisha and B. Mond, "The degree of convergence of sequences of linear positive operators", Proc. Nat. Acad. Sci. U.S.A. 60 (1968), 1196-1200.

Rensselaer Polytechnic Institute,

Department of Mathematical Sciences,

Troy,

New York,

USA 12181

and

University of Duisburg,

Department of Mathematics,

D-4100 Duisburg 1,

West Germany. 